\title{
Estimation of Chaperone-Like Activity Using Test Systems Based on Protein Amyloid Aggregation
}

\section{Boris I. Kurganov*}

Bach Institute of Biochemistry, Russian Academy of Sciences, Moscow, Russia

\section{Introduction}

The main function of small heat shock proteins (sHsps) is suppression of accumulation of protein aggregates in the cell [1-3]. A classic example of protective action of human sHsps is sustaining transparence of lens through whole life [4]. This function in lens is fulfilled by a-crystallin capable of binding the proteins that have lost their native structure. To characterize anti-aggregation (chaperonelike) activity of sHsps, different test systems based on amorphous or amyloid aggregation of protein substrates are used. The quantitative estimation of anti-aggregation activity of chaperones allows the strict comparison of the protective effects of chaperones of different classes to be carried out. Besides, such quantitative approaches provide the necessary background to the elucidation of the mechanism of chaperone functioning.

The methods of quantification of the chaperone-like activity using test systems based on amorphous aggregation of target proteins have elaborated in the articles by Kurganov and coworkers [5-8]. When the kinetics of aggregation of the target protein is followed by the increase of the light scattering intensity $(I)$ or apparent optical absorbance $(A)$, the initial part of the kinetic curve can be described by a quadratic equation [5]:

$$
I=I_{0}+v\left(t-t_{0}\right)^{2} \text { or } A=A_{0}+v\left(t-t_{0}\right)^{2},\left(t>t_{0}\right)
$$

where $I_{0}$ is the initial value of the light scattering intensity, $A_{0}$ is the initial value of the apparent optical absorbance (at $t=0$ ), $t_{0}$ is the duration of the lag phase and $v$ is a constant. Suppose that the apparent optical absorbance (or the light scattering intensity) is proportional to the amount of the protein in the aggregated form. Such a proportionality between absorbance and the amount of the aggregated protein was experimentally demonstrated, for example, by Finke et al. [9] when they studied aggregation of the mutant form of interleukin $1 \beta$ K97I, accompanying refolding of the protein after denaturing action of guanidine hydrochloride. If this supposition is fulfilled, $v$ can be considered as a parameter characterizing the initial rate of aggregation.

The theoretical substantiation of a quadratic dependence was obtained in $[5,10]$ where the model of nucleation-controlled aggregation was analyzed. According to the kinetic scheme considered by Kurganov [5], the native protein undergoes unfolding with the formation of the denatured molecules that are prone to aggregation. The lag phase on the kinetic curve corresponds to the formation of nuclei. The further growth of aggregates proceeds as a result of the attachment of the denatured molecules to the nucleus. If the concentration of nuclei remains constant and the appearance of the denatured form proceeds linearly in time, the accumulation of the aggregated protein should follow the quadratic law.

To characterize the anti-aggregation activity of chaperones, the initial rate of aggregation of a target protein versus the chaperone concentration plots should be constructed. In the case of the protein chaperones forming tight complexes with the target protein the dependence of the relative initial rate of aggregation $\left(v / v_{0}\right)$ on the ratio of molar concentrations of chaperone and target protein ( $x=$ [chaperone]/ [target substrate]) allows determining the adsorption capacity (AC) of chaperone with respect to the target protein. The initial adsorption capacity $\left(\mathrm{AC}_{0}\right)$ can be calculated from the initial linear part of the dependence of $v / v_{0}$ on $x$ in accordance with the following equation [7]

$$
v / v_{0}=1-\mathrm{AC}_{0} x .
$$

The reciprocal value of the length cut off on the abscissa axis by the linear dependence of $v / v_{0}$ on $x$ gives the $\mathrm{AC}_{0}$ value which can be considered as a measure of the anti-aggregation activity of the protein chaperone. The chaperone-like activity of $\alpha$-crystallin was estimated by such a way in $[8,11,12]$ where the following test systems were used: dithiothreitol (DTT)-induced aggregation of bovine serum albumin (BSA) [8] and a-lactalbumin [12] and thermal aggregation of apoglycogen phosphorylase $b$ at $37^{\circ} \mathrm{C}$ [11]. It should be noted that the dependence of $v / v_{0}$ on the [a-crystallin]/[target substrate] ratio was nonlinear indicating that the decrease in the adsorption capacity of a-crystallin occurred with increasing the [-crystallin]/[target substrate] ratio. Such a nonlinearity can be interpreted as an evidence for dynamic $a$-crystallin structure and polydispersity of $a$-crystallintarget protein complexes. From the initial parts of the dependences of $v / v_{0}$ on the [a-crystallin]/[target substrate] ratio the $\mathrm{AC}_{0}$ values were calculated: $\mathrm{AC}_{0}=2.5 \mathrm{BSA}$ monomers per one -crystallin subunit [8], $\mathrm{AC}_{0}=1.18$ molecules of $\alpha$-lactalbumin per one $\alpha$-crystallin subunit [12] and $\mathrm{AC}_{0}=0.86$ apoglycogen phosphorylase $b$ monomers per one $a$-crystallin subunit [11]. The initial adsorption capacity was used in [8] for comparison of the chaperone-like activities of intact -crystallin and $\alpha$-crystallin cross-linked by glutaraldehyde. BSA unfolded by disruption of disulphide bonds under the action of DTT was used as a target protein in this work. It was shown that cross-linking resulted in 12-fold decrease in the $\mathrm{AC}_{0}$ value.

In the case of low-molecular-weight chemical chaperones forming readily dissociable complexes with the target protein the analysis of the dependence of the initial rate of aggregation on the chemical chaperone concentration ([L]) allows determining the semi-saturation concentration $\left([\mathrm{L}]_{0.5}\right)$. The following equation can be used for the description of the dependence of $v / v_{0}$ on [L] [8]:

$$
\frac{v}{v_{0}}=\frac{1}{1+\left([\mathrm{L}] /[\mathrm{L}]_{0.5}\right)^{h}},
$$

*Corresponding author: Boris I Kurganov, Bach Institute of Biochemistry, Russian Academy of Sciences, Moscow, Russia, Tel: +7(495)952-5641; Fax: +7(495)954-2732; E-mail: kurganov@inbi.ras.ru

Received: October 13, 2014; Accepted: November 14, 2014; Published November 16, 2014

Citation: Kurganov BI (2014) Estimation of Chaperone-Like Activity Using Test Systems Based on Protein Amyloid Aggregation. Biochem Anal Biochem 4: 160 doi: 10.4172/2161-1009.1000160

Copyright: (c) 2014 Kurganov BI. This is an open-access article distributed unde the terms of the Creative Commons Attribution License, which permits unrestricted use, distribution, and reproduction in any medium, provided the original author and source are credited. 
where $h$ is the Hill coefficient and $[\mathrm{L}]_{0.5}$ is the $[\mathrm{L}]$ value at which $v /$ $v_{0}=0.5$. Parameter $[\mathrm{L}]_{0.5}$ can be used as a measure of the anti-aggregation activity of the chemical chaperone. When studying the suppression of DTT-induced aggregation of BSA by arginine [8], the following values of parameters $[\mathrm{L}]_{0.5}$ and $h$ were found: $[\mathrm{L}]_{0.5}=116 \mathrm{mM}$ and $h=1.6(0.1 \mathrm{M}$ Na-phosphate buffer, $\left.\mathrm{pH} 7.0 ; 45^{\circ} \mathrm{C}\right)$. The fact that the Hill coefficient is higher than unity is indicative of the positive cooperative interactions upon binding of arginine to the unfolded protein. Such a cooperative binding can be due to clusterization of arginine molecules on the surface of the unfolded protein molecule. The formation of arginine clusters on the surface of the protein molecule has been proved experimentally by Vagenende et al. [13].

Protein aggregation is associated with many neurodegenerative diseases including Alzheimer's, Parkinson's and Type II diabetes. The natively structured or unstructured proteins adopt partially folded conformation and subsequently self-associates through nucleation dependent polymerization to form amyloid fibrils which are characterized by cross- $\beta$-sheet rich structure and capable of binding the amyloidophilic fluorophores thioflavin $\mathrm{T}(\mathrm{ThT})$ and Congo red [14-18]. These fibrils are very stable, resistant to proteases and to harsh environmental conditions. Many natural polypeptide chains are able to form amyloid fibrils in vivo or in vitro, and this ability has been suggested to represent an inherent consequence of the chemical structure of the polypeptide chain.

In the works by Kamihira et al. [19] and Sabaté et al. [20] the fibrillation process was considered as an autocatalytic process with a nucleation reaction followed by an elongation one with the rate constants $k_{\mathrm{n}}$ and $k_{\mathrm{e}}$, respectively. The following equation was obtained for the dependence of the portion of aggregated protein $(f)$ on time [19]:

$$
f=\frac{\rho\{\exp [(1+\rho) k t]-1\}}{\{1+\rho \exp [(1+\rho) k t]\}},
$$

where $k=k_{\mathrm{e}} a$ ( $a$ is the initial protein concentration) and $\rho=k_{\mathrm{n}} / k$. This equation was used, for example, for the description of the kinetics of aggregation of $\beta$-amyloid peptide registered by the increase in the apparent optical absorbance at $400 \mathrm{~nm}\left(37^{\circ} \mathrm{C}\right)$ [20]. To analyze the dependence of the apparent optical absorbance on time, Equation (4) can be modified as follows [21]:

$$
A=A_{0}+K_{3} \frac{K_{2}\left[\exp \left(K_{1} t\right)-1\right]}{1+K_{2} \exp \left(K_{1} t\right)}
$$

where $A$ and $A_{0}$ are the current and initial values of the apparent optical absorbance, $K_{1}, K_{2}$ and $K_{3}$ are constants. Parameter $K_{3}$ is the total increase in the $A$ value in course of aggregation.

To characterize the shape of the kinetic curve, we can use the following parameters: parameter $(\mathrm{d} A / \mathrm{d} t)_{\max }$ which is the slope of the tangent to the kinetic curve at the inflexion point and parameter $t_{1}$ which is the length cut off by this tangent at the horizontal line $A=A_{0}$ (Figure 1). Following determination of constants $K_{1}, K_{2}$ and $K_{3}$ by fitting Equation (5) to the experimental data, parameters $(\mathrm{d} A / \mathrm{d} t)_{\max }$ and $t_{1}$ can be calculated using the following formulae:

$$
\begin{aligned}
& \left(\frac{\mathrm{d} A}{\mathrm{~d} t}\right)_{\max }=\frac{K_{1} K_{3}\left(1+K_{2}\right)}{4}, \\
& t_{1}=\frac{1}{K_{1}}\left[\ln \left(\frac{1}{K_{2}}\right)-\frac{2\left(1-K_{2}\right)}{1+K_{2}}\right] .
\end{aligned}
$$

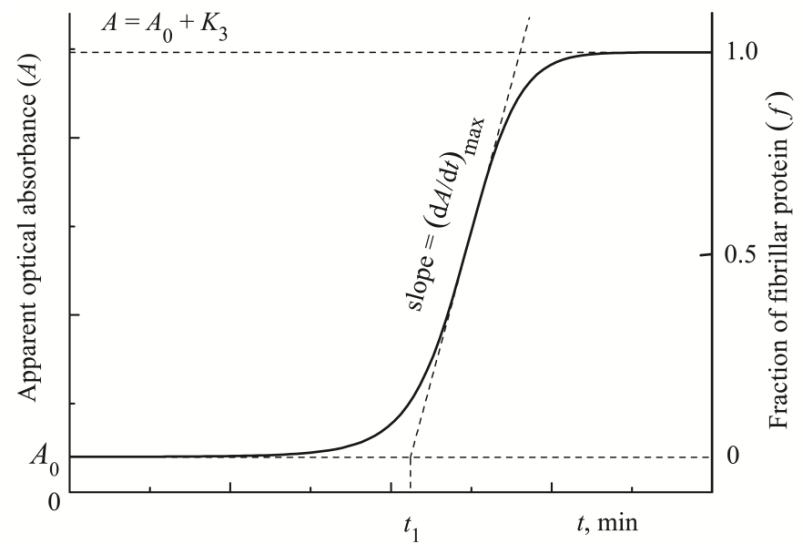

Figure 1: A typical sigmoid curve describing the kinetics of amyloid formation. The use of Equations (5)-(7) for analysis of the kinetics of protein fibrillation.

Parameter $(\mathrm{d} A / \mathrm{d} t)_{\max }$ may be considered as a measure of the aggregate growth rate. Parameter $t_{1}$ is usually called a lag-period (see, for example, the analysis of the correlation between lag time and growth rate in the spontaneous formation of amyloid-like aggregates and fibrils [22]).

It is significant that the use of Equation (5) for description of the full kinetic curve means that the initial increase in the apparent optical absorbance proceeds at $t=0$. In other words, it is beyond reason to believe that the kinetic curve begins with a lag phase characterizing by the $t_{0}$ value different from zero.

Caramelo et al., were first to demonstrate the applicability of the quadratic equation for the description of the initial parts of the kinetic curves for aggregation processes leading to the formation of amyloid fibrils using lysozyme fibrillation as an example [23]. The kinetics of lysozyme fibrillation was monitored by the measurement of the increment of ThT fluorescence $(F)$. The increase in the fluorescence intensity at $482 \mathrm{~nm}$ is proportional the amount of amyloid fibrils [24]. The following modified form of Equation (1) can be used for the analysis of the fibrillation kinetics:

$$
F=F_{0}+v\left(t-t_{0}\right)^{2},\left(t>t_{0}\right)
$$

where $F_{0}$ is the initial value of ThT fluorescence, $t_{0}$ is the lag period and $v$ is a parameter characterizing the initial rate of fibrillation.

Figure 2 shows the application of Equation (8) to the description of the initial part of the kinetic curve of lysozyme fibrillation registered by the increase in ThT fluorescence ([lysozyme $]=2.5 \mathrm{mg} / \mathrm{ml}$ ). The fitting procedure gives the following values of parameters: $F_{0}=0.028, t_{0}=21.6 \pm$ $0.2 \mathrm{~min}$ and $v=(1.43 \pm 0.02) \cdot 10^{-3} \mathrm{~min}^{-2}$.

The applicability of the quadratic law to the description of the initial part of the kinetic curve of amyloid fibril formation was discussed also for fibrillation of insulin $\left(25 \mathrm{mM} \mathrm{HCl}, 0.1 \mathrm{M} \mathrm{NaCl}, 60^{\circ} \mathrm{C}\right)$ [25].

The use of Equation allows performing the quantitative estimation of the effects of different agents on the rate of the fibrillation process. The fibrillation process can be controlled by binding of the specific ligands to the initial native form of the target protein or by binding of the protein or chemical chaperones to the unfolded protein forms. Consider, for example, the retardation of lysozyme fibrillation by natural inhibitors, namely by $\mathrm{N}, \mathrm{N}^{\prime}$-diacetylchitobiose and $\mathrm{N}, \mathrm{N}^{\prime}, \mathrm{N}^{\prime \prime}$ triacetylchitobiose ([lysozyme $]=0.5 \mathrm{mg} / \mathrm{ml} ;[23])$. The effect of these 
Citation: Kurganov BI (2014) Estimation of Chaperone-Like Activity Using Test Systems Based on Protein Amyloid Aggregation. Biochem Anal Biochem 4: 160. doi: 10.4172/2161-1009.1000160

inhibitors is demonstrated in Figure 3. Fitting of Equation (8) to the experimental data gave the following values of parameters $t_{0}$ and $v: t_{0}=52.2 \pm 0.1 \mathrm{~min}$ and $v=(4.24 \pm 0.04) \cdot 10^{-5} \mathrm{~min}^{-2}$ in the absence of inhibitors, $t_{0}=90.8 \pm 0.4 \mathrm{~min}$ and $v=(2.13 \pm 0.01) \cdot 10^{-5} \mathrm{~min}^{-2}$ in the presence of $\mathrm{N}, \mathrm{N}^{\prime}$-diacetylchitobiose and $t_{0}=161.3 \pm 0.2 \mathrm{~min}$ and $v=(3.05$ $\pm 0.03) \cdot 10^{-5} \mathrm{~min}^{-2}$ in the presence of $\mathrm{N}, \mathrm{N}^{\prime}, \mathrm{N}^{\prime \prime}$-triacetylchitobiose. Thus, the protective effect of these natural inhibitors of lysozyme is due to the decrease in the initial rate of aggregation expressed by parameter $v$ and the increase in the lag period (parameter $t_{0}$ ).

In conclusion, it should be emphasized that the quantitative approaches to the estimation of the initial rate of the aggregation process and the duration of the lag phase provide the task-oriented screening

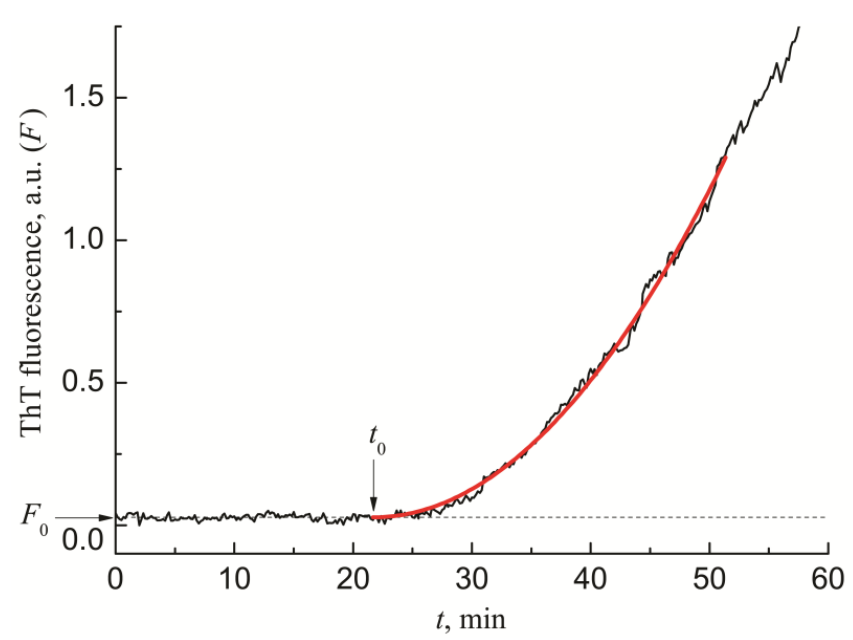

Figure 2: Application of Equation (8) to analysis of the initial part of the kinetic curve for lysozyme fibrillation. The dependence of ThT fluorescence on time.

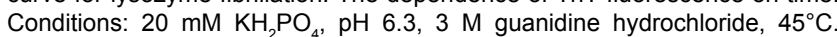
Lysozyme concentration was $2.5 \mathrm{mg} / \mathrm{ml}$. The black line corresponds to the experimental data [23]. The red line is drawn using Equation (8) at $F_{0}=0.028$, $\mathrm{t}_{0}=21.6 \mathrm{~min}$ and $\mathrm{v}=1.4310^{-3} \mathrm{~min}^{-2}$.

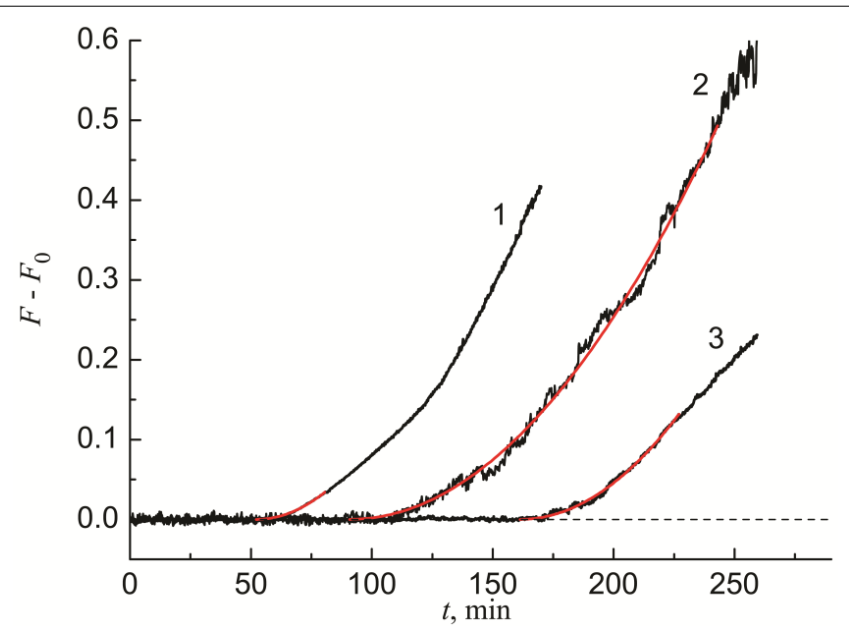

Figure 3: Effect of inhibitors on lysozyme fibrillation. The dependences of ThT fluorescence $\left(F-F_{0}\right)$ on time obtained in the absence of any additives (curve 1) and in the presence of $3 \mathrm{mM} \mathrm{N}, \mathrm{N}^{\prime}$-diacetylchitobiose (curve 2) or $1 \mathrm{mM} \mathrm{N}, \mathrm{N}^{\prime}, \mathrm{N}^{\prime \prime}$-triacetylchitobiose (curve 3). Conditions: $20 \mathrm{mM} \mathrm{KH}_{2} \mathrm{PO}_{4}, \mathrm{pH}$ $6.3,3 \mathrm{M}$ guanidine hydrochloride, $45^{\circ} \mathrm{C}$. Lysozyme concentration was $0.5 \mathrm{mg}$ / $\mathrm{ml}$. The black lines correspond to the experimental data [23]. The red lines are drawn using Equation (8). of the agents which act as efficient suppressors of protein aggregation and are of interest to biotechnologists and specialists in medicinal chemistry elaborating the drugs for treatment of neurodegenerative diseases.

Author is thankful to Dr. J.J.Caramelo (Fundación Instituto Leloir, Buenos Aires, Argentina) for providing the original experimental data on the kinetics of lysozyme fibrillation.

\section{Acknowledgements}

This study was funded by the Russian Foundation for Basic Research (grant 14-04-01530-a) and the Program "Molecular and Cell Biology" of the Presidium of the Russian Academy of Sciences.

\section{References}

1. Van Montfort R, Slingsby C, Vierling $E$ (2001) Structure and function of the small heat shock protein/alpha-crystallin family of molecular chaperones. Adv Protein Chem 59: 105-156.

2. Mymrikov EV, Seit-Nebi AS, Gusev NB (2011) Large potentials of small hea shock proteins. Physiol Rev 91: 1123-1159.

3. Garrido C, Paul C, Seigneuric R, Kampinga HH (2012) The small heat shock proteins family: the long forgotten chaperones. Int J Biochem Cell Biol 44 1588-1592.

4. Clark AR, Lubsen NH, Slingsby C (2012) sHSP in the eye lens: crystallin mutations, cataract and proteostasis. Int J Biochem Cell Biol 44: 1687-1697.

5. Kurganov $\mathrm{BI}$ (1998) Kinetics of heat aggregation of proteins. Biochemistry (Mosc) 63: 364-366.

6. Kurganov $\mathrm{BI}$ (2013) How to quantify the chaperone-like (anti-aggregation) activity? Biochem Anal Biochem 2: e136.

7. Kurganov $\mathrm{BI}$ (2013) Antiaggregation activity of chaperones and its quantification Biochemistry (Mosc) 78: 1554-1566.

8. Borzova VA, Markossian KA, Kara DA, Chebotareva NA, Makeeva VF, et al (2013) Quantification of anti-aggregation activity of chaperones: a test-system based on dithiothreitol-induced aggregation of bovine serum albumin. PLoS One 8: e74367.

9. Finke JM, Roy M, Zimm BH, Jennings PA (2000) Aggregation events occur prior to stable intermediate formation during refolding of interleukin 1 beta Biochemistry 39: 575-583.

10. Ferrone $\mathrm{F}$ (1999) Analysis of protein aggregation kinetics. Methods Enzymo 309: $256-274$

11. Eronina TB, Chebotareva NA, Roman SG, Kleymenov SY, Makeeva VF et al. (2014) Thermal denaturation and aggregation of apoform of glycogen phosphorylase b. Effect of crowding agents and chaperones. Biopolymers 101 504-516.

12. Borzova VA, Markossian KA, Muranov KO, Polyansky NB, Kleymenov SYu et al. (2014) Quantification of anti-aggregation activity of UV-irradiated alphacrystallin. Int J Biol Macromol.

13. Vagenende V, Han AX, Mueller M, Trout BL (2013) Protein-associated cation clusters in aqueous arginine solutions and their effects on protein stability and size. ACS Chem Biol 8: 416-422.

14. Murphy RM (2002) Peptide aggregation in neurodegenerative disease. Annu Rev Biomed Eng 4: 155-174.

15. Nilsson MR (2004) Techniques to study amyloid fibril formation in vitro Methods 34: 151-160.

16. Harris JR, Milton NG (2012) Introduction and technical survey: protein aggregation and fibrillogenesis. Subcell Biochem 65: 3-25.

17. Dobson CM (2013) The amyloid phenomenon and its significance. In: Otzen DE (Ed) Amyloid Fibrils and Prefibrillar Aggregates. Molecular and Biological Properties. Wiley VCH Verlag, Weinheim, 1-19.

18. Breydo L, Uversky VN (2014) Molecular mechanisms of protein misfolding In: Uversky VN, Lyubchenko YL (Eds) Bio-nanoimaging. Protein Misfolding \& Aggregation. Elsevier Inc., Amsterdam, 1-14. 
Citation: Kurganov BI (2014) Estimation of Chaperone-Like Activity Using Test Systems Based on Protein Amyloid Aggregation. Biochem Anal Biochem 4: 160. doi: 10.4172/2161-1009.1000160

Page 4 of 4

19. Kamihira M, Naito A, Tuzi S, Nosaka AY, Saitô H (2000) Conformational transitions and fibrillation mechanism of human calcitonin as studied by highresolution solid-state $13 \mathrm{C}$ NMR. Protein Sci 9: 867-877.

20. Sabaté R, Gallardo M, Estelrich J (2003) An autocatalytic reaction as a model for the kinetics of the aggregation of beta-amyloid. Biopolymers 71: 190-195.

21. Chebotareva NA, Eronina TB, Roman SG, Poliansky NB, Muranov KO, et al. (2013) Effect of crowding and chaperones on self-association, aggregation and reconstitution of apophosphorylase b. Int J Biol Macromol 60: 69-76.
22. Fändrich $M$ (2007) Absolute correlation between lag time and growth rate in the spontaneous formation of several amyloid-like aggregates and fibrils. J Mol Biol 365: 1266-1270.

23. Pagano RS, López Medus M, Gómez GE, Couto PM, Labanda MS, et al. (2014) Protein fibrillation lag times during kinetic inhibition. Biophys J 107: 711-720.

24. LeVine H 3rd (1999) Quantification of beta-sheet amyloid fibril structures with thioflavin T. Methods Enzymol 309: 274-284.

25. Foderà V, Librizzi F, Militello V, Navarra G, Vetri V et al. (2011) Nucleation mechanisms and morphologies in insulin amyloid fibril formation. In: Stein DA (Ed) Protein Aggregation. Nova Science Publishers Inc., New York, 111-137. 